\title{
CHALLENGES IN ENGINEERING DESIGN EDUCATION: VERTICAL AND LATERAL LEARNING
}

\author{
Aleksander Czekanski ${ }^{1}$, Maher Al-Dojayli ${ }^{2}$ and Tom Lee ${ }^{3}$ \\ ${ }^{1}$ Department of Mechanical Engineering, York University \\ ${ }^{2}$ Hatch Ltd. \\ ${ }^{3}$ Quanser
}

Corresponding Author: alex.czekanski@lassonde.yorku.ca

\begin{abstract}
Engineering practice and design in particular have gone through several changes during the last two decades whether due to scientific achievements including the evolution in novel engineering materials, computational advancements, globalization and economic constraints as well as the strategic needs which are the drive for innovative engineering. All these factors have impacted and shaped to certain extent the educational system in North America and Canada in particular. Currently, high percentage of the engineering graduates would require extensive training in industry to be able to conduct reliable complex engineering designs supported by scientific verification and validation, understand the complete design stages and phases, and identify the economic and cultural impact on such designs. This task, however, faces great challenges without educational support in such vastly changing economy.

Lots of attention has been devoted to engineering design education in the recent years to incorporate engineering design courses supported by team design projects and capstone projects. Nevertheless, the lack of integrated education system towards engineering design programs can undermine the benefits of such efforts. In this paper, observations and analysis of the challenges in engineering design are presented from both academic and industrial points of view. Furthermore, a proposed vertical and lateral engineering education program is discussed. This program is structured to cover every year of the engineering education curricula, which emphasizes on innovative thinking, design strategies, support from and integration with other technical engineering courses, the use of advanced analysis tools, team collaboration, management and leadership, multidisciplinary education and industrial involvement. Its courses have just commenced for freshmen engineering students at the newly launched Mechanical Engineering Department at the Lassonde School of Engineering, York University.
\end{abstract}

Keywords: Engineering Design Education: Vertical and Lateral Learning: Product Design: Globalization: Innovative Engineering

\section{INTRODUCTION}

Globalization and global product supply chain characterize modern product development driven by the commoditization of knowledge, and accessibility of low cost engineering talents, mostly from emerging economies [1]. The search for sourcing, however, introduces major challenges that often interfere with the strategic objectives of the corporations that introduce such initiatives [2]. As a result, engineering design faces a number of challenges to: (i) address the customer needs, (ii) increase market share and profitability in this competitive market and (iii) ensure that the requirements of diverse communities and governments existing within global supply chains are satisfied [1].

In order to achieve these objectives, engineering designs have to meet or exceed customer expectations in a robust manner, be innovative and cost efficient, comply with government regulations, address environmental and community issues and create job market. Basically, there is a need for a differentiator engineering design. Key variables in this equation are the continuous scientific and technological engineering advancements. The introduction of nano-reinforced composites, microelectromechanical systems (MEMS), smart polymers, energy harvest systems and additive manufacturing are few examples of many that dictate today's academic research in engineering and has the potential in providing the strength in market competitiveness. Furthermore, economics, regulations, market flexibility, product commonization and environmental impact are also design variables that need to be included in the product and process design cycles. In addition, with the shift in responsibility for design and 
manufacturing processes from the Original Equipment Manufacturers (OEMs) to part suppliers, especially in small to medium enterprises (SMEs), efficient, flexible and sustainable product and process design cycles have become of vital importance.

With no doubt, industrial experience can contribute significantly in shaping how new engineering graduates think about design as a whole system, design cycle, innovation, uncertainties, challenges, design tools and analyses, problem solving and economics. Maturity in design engineering depends on two main elements; (i) general design engineering knowledge and skills and (ii) product or process specific engineering knowledge. These skills can take years to develop. The question is how to provide an educational environment and system such that engineering students graduate with good grasp of general engineering design skills, practical engineering design exercises, new technologies and advanced materials as well as strong fundamental engineering understanding and skills with freedom in thinking towards innovation.

The main drive of this paper is to discuss engineering design education and answer the aforementioned question in order to address the needs, expectations and planning of the engineering graduates, academic institutions and industry, and the strategic planning of the Canadian government towards flourishing and stronger economic future and job market.

\section{ACADEMIC RESEARCH AND INDUSTRIAL GENERAL VIEW OF NEW ENGINEERING GRADUATES}

In order to evaluate any design engineering education system, it is important to evaluate the skills and design engineering ability of the current engineering graduates. Based on the authors' broad experience with new graduate students in many engineering design disciplines including academia, automotive industry, nuclear industry, industrial consulting engineering, testing equipment and control systems, the following general comments can be made:

- There is a general lack of understanding design engineering cycles.

- There is a general weakness in understanding fundamental technical engineering subjects and lack of experience in implementing such fundamentals to real life applications.

- Trends in oversimplification, thus solving a different problem.

- Lack of thinking outside the box.

- Limited knowledge of advanced engineering analysis tools, mostly drafting.

- No verification and validation skills
- Limited use of books, references, and published literature.

- Depending on workplace, coop programs can be valuable.

- Universities' extracurricular design team work sessions are beneficial.

- Exceptional high class marks do not always reflect the excellence of new engineering graduates.

It is important to mention that the above remarks are general and do not necessarily apply to all students.

Indeed, a number of top class students with good technical coop programs and extracurricular design team work showed to be excellent in handling problem solving and most importantly the freedom to think. It is worth noting that a number of the above listed observations, made by the authors, were captured in the published literature, see for example [3] and [4].

Furthermore, it is important to allude to the advancement in engineering simulation tools (for example, Computer Aided Engineering) and its contribution to engineering design in which physics and problem settings closer to reality can be solved. With the goal of offering software packages to be used by every engineer, providers of commercial dynamic simulation control systems, design optimization, Finite Element Analysis (FEA) and Computational Fluid Dynamics (CFD) software have developed user friendly interfaces with many default settings to reach "a converged solution". Hence, their use can be very risky if there is a lack and/or improper understanding of such important engineering analysis tools and training along with the inadequacy of understanding fundamental engineering subjects, verification and validation.

Therefore, there is a need to establish and evaluate an engineering design education system that addresses all the aforementioned concerns.

\section{EXISTING ENGINEERING DESIGN EDUCATION}

Challenges in design engineering education have been recognized and addressed in the open literature [3]. Many attempts have been made in academic institutions to change the way design is taught and its integration in the academic curricula and capstone projects.

For example, Distributed Innovative Design, Education, and Teamwork (DIDET) Framework was introduced through the development of a digital library, conducted by the University of Strathclyde, Stanford University, and Olin College [5]. The goal has been to enhance student learning opportunities through global team-based design engineering projects, experiencing open and innovative thinking, cultural and social challenges. The role of engineering design in engineering 
curricula, specifically the interdisciplinary and multidisciplinary aspects of the design, was also emphasized through engineering design centers such as Engineering Design Research Center (EDRC) at Carnegie Mellon University (CMU), Center for Design Research (CDR) and Center for Integrated Facility Engineering (CIFE) at Stanford [6].

In the course of interviewing many second and third year coop engineering students, conducted by the authors, there was a common answer to a question about students' favorite course. It was mainly about applied engineering courses. Students appreciate the experience of applying engineering fundamentals to real or semi-real problems. By the same token, there is a great recognition by the students to understand the general layout and reasons behind studying, analyzing and/or conducting any project whether during their school work or during their coop work terms.

This reality was addressed to some extent by an idea of offering a common first year course taken in the first semester of the freshman year at the School of Engineering and Applied Science (SEAS) at Miami University, covering general information on computing, engineering and society, attended by students from all engineering disciplines [7]. It can help students to understand and appreciate engineering design process and what is required to reach a level that allows such engineering design with confidence. In addition, students can identify at early stages the key elements of engineering professionalism including code of ethics, ethical and societal matters and their impact on society, at the national and global levels.

Integration of engineering design and other disciplines such as industrial engineering has been recognized through problem-based project work and cross-faculty collaboration [8]. A new pedagogy was developed at Swinburne University of Technology, at which a design course was created through faculty collaboration. It was believed that $100 \%$ of students' employment rate was attributed to attending this course.

In a study on students' project design activities, a comparison was made between first year and senior twosemester capstone projects [9]. Preliminary results showed that freshman students spent much of their normalized time on problem definition, assumptions and constraints, and brain storming and idea generation. On the other hand, senior design students spent more of their normalized time working on brainstorming/design concepts, detailed design/communication, and production, but relatively less time on research/testing/analysis and modeling/prototyping, and model/prototype evaluation.

It is important to note that although creativity and innovative thinking are key elements for future engineering design, they are not sufficient for a successful design. Indeed, it is the successful integration of all design activities and the associated gained skills and experience that can answer majority of the current concerns in engineering design. The impact of weak understanding and/or inadequate application of fundamental engineering subjects in design projects is much higher in Small to Medium Enterprises (SMEs) compared to large corporations in which there are welldefined product design cycle methodologies and support for advanced engineering analyses. With globalization and economic challenges, there is paradigm shift in industry to transfer product development of many parts from OEMs to SMEs.

With the high population ratio of SMEs to OEMs in Canada, the impact of future design engineering and associated employment is high. Furthermore and in an attempt to provide ground for scientific and technological advancements, many new graduate courses have been developed and are being offered on the expense of advanced core engineering courses that are still highly needed.

\section{VERTICAL AND LATERAL ENGINEERING DESIGN EDUCATION}

A Vertical and Lateral Learning system (VLL) in engineering design education incorporates the strength of a number of existing education systems and also integrates with the fundamental core engineering courses, as shown in Figure 1.

The solid core base of this system covers product and/or process design cycles and methodologies, problem solving techniques, engineering drawings, machine elements design and system engineering. It should provide the students with a structured layout of the engineering design activities and what it takes to have a design.

Laterally, it promotes concept development, creative and innovative thinking through open-ended project oriented problems, capstone design project, industry engagement, machine workshops. It also facilitates the integration and application of basic and interdisciplinary engineering courses, including design economics, social and environmental impact, ethics and regulatory issues, and global and cultural impact. Mini design projects will be attended through an industrial working cell model in which a team is assembled representing a lead, an engineering team, a designer and a financial manager. This dynamic team will eventually provide a design, recorded activities including meeting minutes, challenges, practical experience gained through these projects, interdisciplinary collaboration with others, and potential improvement of the conducted design activities.

The vertical dimension of this system evolves through the engineering school years with the gained knowledge 


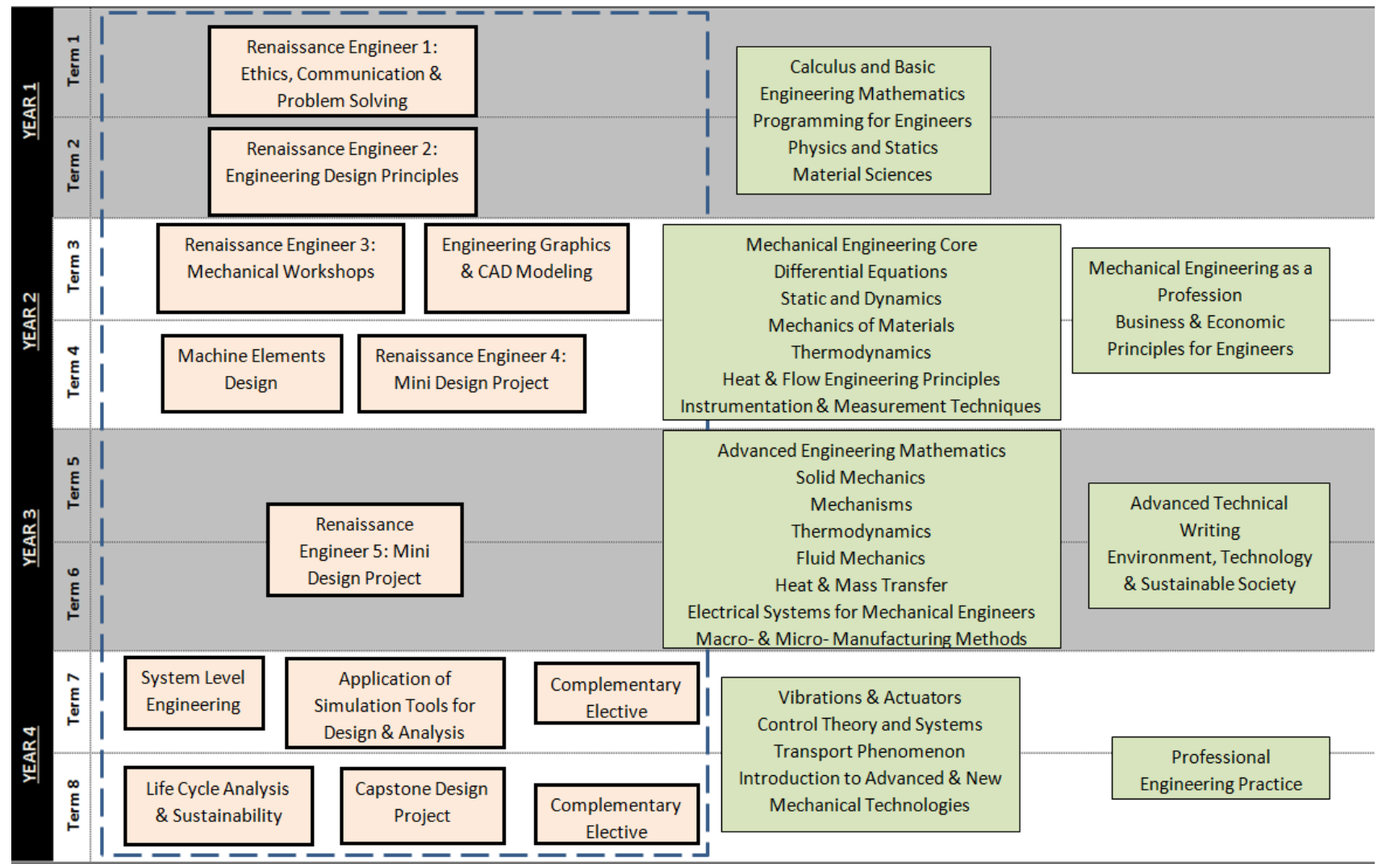

Fig. 1. Schematic of Engineering Design Education with Vertical and Lateral Learning

in engineering analysis tools. Design analysis tasks conducted in the second academic year will be using basic engineering analysis tools. In this case, students will have to simplify their problems such that basic engineering skills can be utilized. In order to prevent over-simplifications, students will have to support their assumptions through the verification and validation of the analyses using other forms of solution techniques, measurements and testing. In the third academic year, students will be able to witness the power of more detailed and advanced knowledge learnt through the engineering school. This can provide mutual benefits to the students by provoking the interest in learning fundamental engineering and how to apply them with flexibility and freedom to their design projects.

It is crucial that students use these simplified analytical and closed form solutions to be able to provide in depth understanding and confidence in applied engineering analyses. These developed important skills will be used in the fourth year capstone projects to validate the assumptions, analyses and results to be obtained using advanced numerical tools such as FEA and CFD. Furthermore, with the introduction of more core engineering courses such as vibration and control systems, student will be able to relate and use in a simplified manner the life cycle analysis and sustainability of the design.
We believe that the systematic structure of this engineering design education system utilizing the Vertical and Lateral Learning scheme, supported by industrial capstone projects and coop program will offer engineering graduates a more mature and systematic design experience.

With any new educational system, iteration and evolution of the system structure is expected to reach a refined system [10]. This Engineering Design Education system has commenced this year for freshman students at the newly launched Mechanical Engineering Department at the Lassonde School of Engineering, York University. To ensure high educational quality, engineering design education evaluation and effectiveness are being developed to: (i) identify areas of effective practice and areas of the curriculum that promote learning; (ii) identify and explain students and program successes that can be replicated and/or built upon; and (iii) identify gaps and areas for enhancement and suggest improvements. These evaluations are relevant to both the vertical and lateral learning schemes. 


\section{CONCLUSIONS}

In this paper, academic and industrial general observations were made in regards to the engineering design capabilities of new engineering graduates. In order to address the challenges in engineering design and narrow the gaps in academic, industrial and students' expectations, an engineering design education is presented utilizing vertical and lateral learning. We believe that the presented approach will not only enhance the students' design skills but also improve their ability in using applied analysis tools and increase awareness and interest in fundamental core engineering courses. This is of special importance when it comes to design education accounting for the shift in responsibility in design and manufacturing processes from the Original Equipment Manufacturers (OEMs) to Small to Medium Enterprises part suppliers (SMEs).

\section{References}

[1] S. Liu and I. Boyle, "Engineering Design: Perspectives, Challenges, and Recent Advances", Journal of Engineering Design, 20, pp. 7-19, February 2009.

[2] S. Manning, J. Sydow and A. Windeler, "Securing Access to Lower-cost Talent Globally: The Dynamics of Active Embedding and Field Structuration”, Regional Studies, 46.9, pp. 1201-1218, October 2012

[3] A. Chisholm, “An Engineering Design Analogy for Engineering Education”, Computers in Industry, 14, pp. 197-204, 1990.
[4] J. Newcomer, "Design: The Future of Engineering and Engineering Technology Education”, 29th ASEE/IEEE Frontiers in Education Conference, (San Juan November 10-13, 1999), Puerto Rico, pp. 14-16, 1999.

[5] A. Wodehouse, H. Grierson, C. Breslin, O. Eris, W. Ion, L. Leifer and A. Mabogunje, "A framework for design engineering education in a global context”, Artificial Intelligence for Engineering Design, Analysis and Manufacturing, 24, pp. 367-378, 2010.

[6] C. Dym, "Design and Design Centers in Engineering Education”, Artificial Intelligence for Engineering Design, Analysis and Manufacturing, 12, pp. 43-46, 1998.

[7] D. Troy, D. Keller, J. Kiper and L. Kerr, "First Year Engineering: Exploring Engineering through the Engineering Design Loop”, 38th ASEE/IEEE Frontiers in Education Conference, (Saratoga Springs, NY, October 22 - 25, 2008), pp. 10-15, 2008.

[8] I. de Vere, G. Melles and A. Kapoor, "Product Design Engineering - A Global Education Trend in Multidisciplinary Training for Creative Product Design”, European Journal of Engineering Education, 35, pp. 33-43, March 2010.

[9] N. Phanthanousy and Y. Allam, "First-Year / Senior Year Design Data: Preliminary Results from Ongoing Research on Post-secondary Design Student Activities”, IEEE Frontiers in Education Conference (FIE) Frontiers in Education Conference, October 2013, pp.1118-1120, 2013.

[10] B. Allenby, "Rethinking Engineering Education”, Proceedings of the 2011 IEEE International Symposium on Sustainable Systems and Technology, May 2011, pp. 1-5, 2011. 